EDITORIAL

\title{
INTEGRAÇÃO DOCENTE-ASSISTENCIAL E A ENFERMAGEM
}

\begin{abstract}
O assunto, atualmente em moda, já foi até codificado - I.D.A. - Integração Docente-Assistencial.

Buscando um sentido amplo, poder-se-ia chegar a um significado de IDA mais abrangente, que envolve o ensino multidisciplinar, na utilização de recursos da comunidade, fora dos muros da Universidade, e em função não apenas do aprendizado mas também do bem estar geral — da saúde - do individuo, fa. milia e comunidade.
\end{abstract}

Em enfermagem esta integração deve traduzir a interdependência entre docentes de enfermagem e enfermeiros de serviços, visando o processo ensino-aprendizagem para o aluno e a assistência à saúde para o indivíduo, sua família e a comunidade.

Se atentarmos, porém, para a História da Enfermagem, não podemos deixar de reconhecer que a integraçã॰ entre ensinar e o cuidar foi sempre a sua própria essência, ou pelo menos o foi, desde que Florence Nightingale, em 1855, associou principios científicos aos cuidados a serem prestados ao enfermo. Estabeleceu Florence uma relação intima entre o ensinar e o cuidar um completando o outro, em verdadeiro sistema de IDA.

Entretanto, na medida em que a Enfermagem evolui como profissão, atingindo a formação do enfermeiro grau universitário, cresceram também as responsabilidades do ensino, tornaram-se mais complexas as tarefas de assistência. Hoje, a enfermagem expandiu-se além da área hospitalar atingindo os Centros de Saúde, deixando de ser apenas uma enfermagem curativa para atuar na área preventiva, buscando envolver a comunidade no que lhe deve tocar de responsabilidade com a saúde. Ainda uma vez o sentido de integração se faz sentir no desenvolvimento de ações de enfermagem.

Especificamente sobre Integração Docente-Assistencial pode-se afirmar que, a partir da Reforma Universitária de 1968, intensificaram-se os estudos sobre sua problemática, e ela foi considerada elemento de suma importância para a qualificação do profissional a ser formado e, conseqüentemente, para a melhoria da assistência de enfermagem a ser prestada.

Uma revisão bibliográfica nos anais da enfermagem brasileira pode mostrar, cronologicamente, como a IDA tem sido motivo da classe. Vejamos:

1968 - Foi recomendação do XX Congresso Brasileiro de Enfermagem a participação do corpo docente e enfermeiros brasileiros entre si, visando melhorar o relacionamento e estabelecer padrões referenciais para os serviços de enfermagem nos hospitais de ensino.

1969 - Da realização pela Escola de Enfermagem da Universidade Federal da Bahia de um Seminário sobre IDA, resultaram conclusões sobre o assunto que ainda permanecem atualizadas.

1971 - O plano Decenal de Saúde Para as Américas (decênio 71-80) faz recomendação para integrar o ensino com serviços de enfermagem. Também a Revista Brasileira de Enfermagem publica artigo de Ribeiro, chamando a atenção para a importância do desenvolvimento de um currículo mais integrado - ensino 
e prática voltados para as necessidades reais de cada sociedade a que se destinam - atender às mudanças do mundo moderno.

1973 - Novamente o XXV Congresso Brasileiro de Enfermagem traz em suas recomendações o entrosamento das escolas com os serviços.

1975 - A Lei 6.229 de 17 de setembro de 1975, que dispõe sobre a organização do Sistema Nacional de Saúde, refere-se à integração e considera os hospitais de ensino instrumentos essenciais na política da IDA.

1977 - E vasto o material sobre o assunto, a partir desse ano $e$ até o presente momento, quando já se tornou habitual a utilização não apenas dos hospitais universitários mas de Instituições de Saúde, como campo de estágios com o objetivo comum de exercer funções educativas, assistenciais $e$ de pesquisa. Tais funções devem proporcionar ao estudante experiências de aprendizagem que lhe permitam: - consolidação de conhecimentos; - capacitação para o trabalho de intercomplementação, ensino e assistência, que deve determinar as ações dos profissionais que atuam na área educação-saúde.

$O$ passeio histórico pretendeu apenas mostrar a quanto tempo e por quantos $o$ assunto vem sendo debatido - hoje tem-se como certo que o processo envolve, não apenas questões administrativas e politicas de grande complexidade, mas também atitudes individuais de compreensão, de aceitação da interdependência que dele decorre.

$E$ preciso que enfermeiros docentes e assistenciais, conscientizem-se da IDA para a melhoria da qualidade do ensino e, conseqüentemente, para a elevação do padrão de saúde da comunidade.

E preciso que os profissionais da área de saúde estejam envolvidos no processo de IDA, no sentido amplo, interdisciplinar, superando suas barreiras pes. soais, caminhando juntos, de espirito desarmado, em função do objetivo comum de ensino - assistência e pesquisa.

M.H.A. 